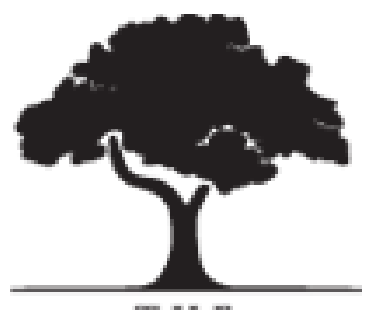

T H E

HASTINGS

C E N T E R

On the Origin of Great Ideas: Science in the Age of Big Pharma

Author(s): Leemon McHenry

Source: The Hastings Center Report, Vol. 35, No. 6 (Nov. - Dec., 2005), pp. 17-19

Published by: The Hastings Center

Stable URL: http://www.jstor.org/stable/3528561

Accessed: 06/06/2013 16:50

Your use of the JSTOR archive indicates your acceptance of the Terms \& Conditions of Use, available at

http://www.jstor.org/page/info/about/policies/terms.jsp

JSTOR is a not-for-profit service that helps scholars, researchers, and students discover, use, and build upon a wide range of content in a trusted digital archive. We use information technology and tools to increase productivity and facilitate new forms of scholarship. For more information about JSTOR, please contact support@ jstor.org.

The Hastings Center is collaborating with JSTOR to digitize, preserve and extend access to The Hastings Center Report. 
research be subject to stronger oversight at both local and national levels. Under these proposals, each institution engaged in embryonic stem cell research would establish an Embryonic Stem Cell Research Oversight (ESCRO) committee to oversee all issues related to the derivation and use of embryonic stem cells, review all proposals for scientific merit, maintain records of research that takes place at the institution, and educate investigators. Local institutional review boards (IRBs) would provide additional oversight, even though much embryonic stem cell research will not, strictly speaking, need to go before an IRB. The guidelines recommend that the procurement of egg, sperm, and embryos always be reviewed by an IRB, regardless of whether federal regulations require it, and that IRBs never waive the requirement for informed consent from a person donating cells, eggs, sperm, or embryos to research, even if the regulations for human subject research provide for such waiver.

The guidelines also call for the establishment of a national oversight body to consider issues of practice and policy on an ongoing basis. Such a body would be similar to the United Kingdom's Human Fertilisation and Embryology Authority and Canada's Stem Cell Oversight Committee, although those national bodies also conduct some local review and oversee assisted human reproduction - an area largely free from national regulation or oversight in the United States and not addressed in these guidelines.

The other significant set of recommendations addresses the involvement of egg, sperm, and embryo donors. In line with much guidance, law, and regulation around the world, the guidelines recommend requiring consent from donors. They go beyond previous U.S. guidance by extending this requirement to those who contributed gametes to an embryo originally created for fertility purposes. Accepting this requirement will rule out the use of some embryos already created for fertility purposes and now in frozen storage.

The guidelines hedge somewhat on whether to compensate egg, sperm, and embryo donors. They note the arguments in favor of compensation: paying egg and sperm donors is routine in the U.S. fertility context, and many Americans participating in other kinds of research are offered financial inducements to secure their participation. The arguments for compensating egg donors are particularly strong: "the invasiveness and risks of the procedure suggest that financial remuneration is most deserved, but at the same time there is a greater likelihood of enticing potential donors to do something that poses some risk to themselves."

Ultimately, however, they follow previous U.S. guidelines and accepted practice in many other nations by recommending that egg donors be reimbursed only for "direct expenses" and that no payment whatsoever be offered to sperm or embryo donors. They also recommend against compensation in kind, including "personal medical benefit" (but excepting autologous transplantation, where the donor receives stem cells derived from his or her own donation). This rule would prevent a kind of egg or embryo sharing arrangement whereby women or couples receive cheaper or free fertility treatment in exchange for donating a portion of their eggs or embryos to stem cell research. The prohibition on compensation extends to fertility clinics, which may only be reimbursed for the costs of obtaining consent and collecting eggs, sperm, or embryos.

Other issues treated in the guidelines include the banking and distribution of cell lines, documentation of research, transmission of personal information associated with donations, and international collaboration. Some of these recommendations are fairly brief and incomplete. Other issues the committee simply flags for further consideration, such as the impact of intellectual property rights on research and access to any eventual treatments. They do not profess to be the final word. Nevertheless, they provide a useful starting point.

\section{On the Origin of Great Ideas:}

\section{Science in the Age of Big Pharma}

\section{BY LEEMON MCHENRY}

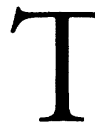

The vision most people used to have of medical research is that professors gain funding from universities or government agencies, go to the lab for careful observation and experiment, and after some years publish their hardwon results in scholarly, peer-reviewed medical journals. This is probably a simplified story that never played out quite as envisioned. As a result of commercial interests in the outcome of medical research, we are now even further from it. Pharmaceutical companies' marketing departments have developed a novel strategy. The old vision allowed costly failures when reality did not cooperate with the company's plans for its new molecular entities. With the rising price of bringing a new drug to the market, a method that guaranteed success was needed. Instead of fitting the conclusion to the evidence, the industry's strategy now is to "defend the molecules": Select the data that promote the drugs, file away the results that are unfavorable, and then buy just the right academic credentials to sign on to ghostwritten articles produced by the marketing department staff or by public relations agencies employed by the company. Publish these articles in the most respected

Leemon McHenry, "On the Origin of Great Ideas: Science in the Age of Big Pharma," Hastings Center Report 35, no. 6 (2005): 17-19. 
medical journals. Complete the circle of evidence by citing the published ghostwritten journal articles in "Dear Doctor" letters and other promotional materials, as if they were independent verification of the effectiveness and safety of the drugs.

To some extent, academic medicine has long involved ghostwriting. Scientific writers have often written up the results of studies. But while this practice deprives the authors of the credit they rightly deserve, it does not threaten to undermine the scientific integrity of medical research. What is relatively new on the scene is industry-sponsored ghostwriting. Drug promotional materials masquerade as legitimate scientific research, and competition between the pharmaceutical companies for the market share is fought out using "key opinion leaders" who are paid to sign on to the ghostwritten articles.

What follows is an account of one such case. The documents that build the case were filed into the public record by GlaxoSmithKline's lawyers on June 23, 2004 (docket numbers 290 and 291) in the In re Paxil Products Liability Litigation MDL 1574. They were then used in an $A B C$ Primetime program on antidepressants that aired on December 9, 2004. ${ }^{1}$ The author is a research consultant for Baum-Hedlund, the Los Angeles-based law firm that filed the suit on behalf of individuals suffering from withdrawal symptoms upon discontinuing Paxil, which is one of the antidepressants known as selective serotonin reuptake inhibitors (SSRIs).

As it turns out, the differences in efficacy among the SSRIs are minimal, so their side effects profiles can make all the difference in how doctors prescribe them. In the mid-1990s, Eli Lilly, which manufactures Prozac (another of the SSRIs), began attacking Paxil, manufactured by GlaxoSmithKlineat that time, SmithKline Beecham —on just these grounds. In 1996-97, Lilly sponsored conferences and journal supplements focusing attention on the side effects caused by Paxil. ${ }^{2}$ Paxil has a short "half-life"- the time after taking a drug at which half of the dose remains in the body-and therefore a short wash-out period when compared to Prozac. Paxil's halflife is twenty-one to twenty-four hours; Prozac's four to sixteen days. Because of the short half-life, a patient who abruptly ceases therapy with Paxil tends to have more severe withdrawal symptoms.

Lilly's strategy was to play up the problems associated with Paxil's short half-life. One key paper sponsored by Lilly was Jerrold F. Rosenbaum and John Zajecka's "Clinical Manage- ment of Antidepressant Discontinuation," presented at a closed symposium titled "SSRI Discontinuation Events" and later published in a supplement of the Journal of Clinical Psychiatry. ${ }^{3}$ In this short paper, Rosenbaum and Zajecka stressed the importance of gradually tapering all SSRIs except fluoxetine (Prozac). They also suggested substituting fluoxetine in cases where symptoms of "discontinuation"-as they now called withdrawal-persevere even when the SSRI is tapered slowly. ${ }^{4}$ Both citations for this claim refer to cases of paroxetine withdrawal.

SmithKline Beecham wasted no time counterattacking. Their "Business Plan Guide," dated December 1, 1997-May 31, 1998, announced new strategies against Lilly, including instructions to sales reps regarding the manner in which they were to address the problem of discontinuation with physicians and psychiatrists. 5 Instructions included bullet points under categories such as "Minimize concerns surrounding discontinuation symptoms" and "Maximize benefits of optimal 24-hour half-life." 6

Part of the SmithKline Beecham response involved the use of the medical journals to get their message into the right hands. The public relations agency Ruder-Finn was hired by SmithKline Beecham's marketing department to help prepare publications in the "Paxil Discontinuation Response." The documents in this case show how Ruder-Finn and SmithKline Beecham's marketing department worked together to disguise the authorship of these publications. In a memo of June 5, 1997, Ruder-Finn wrote to SmithKline Beecham marketing that "Weve written two draft letters to the editor regarding the Lilly discontinuation supplement. One is from Drs. [Bruce G.] Pollock, [Ranga] Krishnan and [Charles B.] Nemeroff. The other would be authored by Ivan [Gergel]."7 Ruder-Finn also notes that letters in Journal of Clinical Psychiatry are written as case reports, so "if this is a requirement, we'll need to ask one of the physicians to provide one." They also note that the references listed for discontinuation symptoms with all SSRIs are the same for both letters, "and complete duplication will look fishy if we decide to submit both." They ask: "Are there other references we could draw on for the various drugs? At the very least, we can't have the references appear in the same order."

Both draft letters make essentially the same points in response to Rosenbaum and Zajecka: (1) discontinuation symptoms have been reported with all SSRIs; (2) discontinuation symptoms with SSRIs are relatively mild and transient; (3) 
symptoms are less severe than those associated with discontinuation of tricyclic antidepressants; (4) incidence of adverse effects after abrupt discontinuation of paroxetine has been very low; and (5) the short half-life of paroxetine is a benefit when flexibility is desired in situations where switching or discontinuation of a medication is required. Both drafts contain handwritten editing by SmithKline Beecham marketing.

One of the two letters was published in the Journal of Clinical Psychiatry under the name of Bruce G. Pollock. ${ }^{8}$ The piece, "Discontinuation Symptoms and SSRIs," is an expanded version of the original Ruder-Finn letter that bears his name but emphasizes points (1) and (2) above, in addition to another point that was in the original draft of this letter-that patients who abruptly stop treatment with a long-acting agent may not associate a symptom that occurs several weeks later with discontinuation of therapy. Overall the letter defends Paxil by showing that SSRIs with longer half-lives, like Prozac, also leave patients with discontinuation symptoms when the patient stops taking them. The letter does not acknowledge that SmithKline Beecham marketing or Ruder-Finn had any role in writing it, nor that Bruce Pollock has any financial relationship to SmithKline Beecham.

The letter was published in October 1998. In SmithKline Beecham's "Business Plan Guide," references to "The Pollack [sic] Letter" show up as part of the marketing strategy for sales reps. Interestingly, the Business Plan Guide appeared well before the letter was published. How SmithKline Beecham knew the letter was forthcoming one can only guess. The Guide says:

This letter to the editor authored by Bruce Pollack [sic], M.D. in the Journal of Clinical Psychiatry, October, 1998 is a great resource for addressing the issue of discontinuation. Dr. Pollack [sic] clarifies that discontinuation symptoms have been reported to occur with all SSRIs with onset and duration mediated by drug half-life. Most importantly, he balances the risk benefit of a short vs. long half-life, noting the control offered by shorter half-life agents. . . . You may order reprints of the Pollack [sic] letter electronically. ${ }^{9}$

The Business Guide also makes it clear that part of the strategy for educating physicians about Paxil should include emphasizing that a short half-life offers the benefit of a "drug holiday." 10 A common side effect of the SSRIs is sexual dysfunction, but the short half-life of Paxil allows a patient to wash the drug out of his system quickly in anticipation of sexual relations.

In a recent House of Commons health committee investigation, witnesses from GlaxoSmithKline strongly denied that the company practiced ghostwriting. Dr. Stuart Dollow, from GlaxoSmithKline, went as far as to state: "The issue of ghostwriting, as alleged, is not something I recognize at all."11 The Journal of Clinical Psychiatry likewise denies that it allows ghostwriting. It claims "to adhere to the highest ethical standards of scholarly peer-review and publication." Journal policy "requires that authors name all persons who have made substantial contributions but who do not fulfill authorship criteria and disclose the named individuals' pertinent professional or financial relationships; contributions include writing or editing assistance. JCP policy requires that all such acknowledgments and disclosures are printed along with the accepted article or letter."12 The "Authorship Statement, Copyright Transfer, Financial Disclosure, and Acknowledgement Permission" form on the journal's website requires disclosure of a range of financial relationships, including consulting relationships, grant/research support, speakers or advisory boards, "and other financial or material support." This policy has been in place since the journal's inception.

One final piece in this collection of documents provides a fitting conclusion to this case study. It appears to be part of a PowerPoint presentation to SmithKline Beecham marketing or sales reps. The slide is headlined: "Discontinuation: why this is an issue." The text reads: "'97 Seroxat/Paxil sales to the end Sept already exceed \$1 BILLION." Below the text is an image of a bag of money. ${ }^{13}$

\section{Acknowledgment}

I wish to thank Gregory Kaebnick, Skip Murgatroyd, and an anonymous referee for the Hastings Center Report for various forms of input to this case study.

1. These documents can be viewed at http://abcnews.go.com/ Health/story?id=311956\&page $=1$.

2. 6th World Congress of Biological Psychiatry, "Interruption or Discontinuation of Antidepressant Therapy: A Critical Consideration in Patient Management," Nice, France, 1997, and "SSRI Discontinuation Events," Phoenix, Arizona, 1996.

3. J.F. Rosenbaum and J. Zajecka, "Clincal Management of Antidepressant Discontinuation," Journal of Clinical Psychiatry 58 (suppl. 7) (1997), 37-40.

4. Ibid., 39.

5. SmithKline Beecham Business Plan Guide, Sales Cycle 2, 1997, December 1, 1997-May 31, 1998, 0290-0297.

6. Ibid., 0264.

7. Sandra Stahl, Ruder-Finn memo, June 5, 1997, 0260.

8. Journal of Clinical Psychiatry 59, no. 10, October 1998, 535-36.

9. SmithKline Beecham Business Plan Guide, 0297.

10. Ibid., 0296.

11. House of Commons Health Committee, The Influence of the Pharmaceutical Industry, Fourth Report of Session 2004-05, volume I, March 22, 2005, 54.

12. Email correspondence from Meg M. Waters, Director of Editorial Services, Physicians Postgraduate Press, April 7, 2005. See "Uniform Requirements for Manuscripts Submitted to Biomedical Journals: Writing and Editing for Biomedical Publication," at www.icmje.org/\#conflicts. pdf. 